\title{
Classroom Teachers' Attitude and Perceived Barriers to Implementation of Sport Science Program in Malaysian Secondary Schools
}

\author{
Eng Hoe Wee \\ Department of BioScience and Sport Science, Tunku Abdul Rahman University College \\ weeeh@acd.tarc.edu.my \\ Ngien Siong Chin
}

Department of Physical Education, the Institute of Teacher Education, Tun Abdul Razak Campus

ngiensiongchin@gmail.com

Hui Yin Ler

Department of BioScience and Sport Science, Tunku Abdul Rahman University College

hyler@acd.tarc.edu.my

\begin{abstract}
This study investigated the barriers toward the implementation of a new sport science curriculum in Malaysian secondary schools. This study is significant for the Ministry of Education Malaysia, as previous researchers (e.g. Ariathan, 1988; Charlesworth, 1975; Croll \& Mosses, 1990; Fetterman et al., 2010; Lynch \& Saifel Islam,1989; Schlairet, 2011) have reported numerous barriers in implementing new curriculum which include resource barrier, untrained staff, leadership and management, and lack of teachers' monitoring and guidance. Participants comprised a purposive sample of 135 schools and 94 teachers in Malaysia. Pencil and paper questionnaire was used to gather data relevant to demographics (gender, age, teaching experience, qualification, specialization, preparedness, orientation course), teachers' attitude toward sport science $(r=0.89$, $n=8)$, teacher related $(r=0.93, n=8)$ and institution related $(r=0.73, n=6)$ perceived barriers to sport science program implementation. The alpha value for the 22 attitude and perception items was 0.73. The sample comprised a majority of male teachers $(81 \%)$ and $85 \%$ of all respondents were under 40 . Half of the respondents were trained in sport science, $30 \%$ in physical education $(P E)$ and $20 \%$ in other subjects. A third of the Sports Science teachers have less than 1 year teaching experience, majority (57.4\%) had $1-2$ years teaching experience and $13.9 \%$ taught 3 years and above. Almost $69 \%$ of SS teachers have attended SS Orientation Course. In terms of teaching preparedness, almost 65\% was poorly prepared and $35 \%$ was prepared and averagely prepared to teach SS. Results identified the key factors inhibiting SS teachers, which were categorized as teacher-related (TR) or institutional related (IR). TR barriers revealed that inability to complete the syllabus and inability to prepare exam papers as substantial while IR showed the suitability of SS reference books was the main barrier. Attitude domain was significant in terms of preparedness. This research findings provide invaluable feedbacks to the ministry of education to improve sport science teachers' attitude toward teaching of sport science and to overcome teacher related and institutional related barriers in improving sport science programme implementation.
\end{abstract}

Index terms: sport science, curriculum implementation, barriers to teaching, programme evaluation

\section{INTRODUCTION}

In exploring complexity of teaching and its effect on quality teaching, greater attention needs to be paid to teachers' attitudes and barriers involved which are central to successful program implementation. This study investigated teacher's attitude and the barriers toward the implementation of a new sport science curriculum in Malaysian secondary schools. This study is significant for the Ministry of Education Malaysia, as previous researchers[1,2,3,4,5] have reported numerous barriers in implementing new curriculum which include resource barrier, untrained staff, leadership and management, and lack of teachers' monitoring and guidance. However, there has been limited research in Malaysia and other countries examining teachers' attitude and perceived barriers toward the teaching of sport science subject in secondary schools. 


\section{METHOD}

\section{A. The participants}

The target population of the present study included sport science teachers from secondary schools that offer sport science as a subject in the school curriculum. Participants comprised a purposive sample of 135 schools and 94 teachers in Malaysia with a response rate of $69.6 \%$. This research examined the pioneer schools that participated in the implementation of SS program thus this explained why the sample size was limited. The sample size was based on the list provided by the Ministry of Education Malaysia.

\section{B. Instrumentation}

Major Barriers Inhibiting the Delivery of Sport Science. A 14-item instrument was developed to determine the factors SS teachers perceived to be the most substantial. Teachers were asked to indicate the strength of each barrier on a scale 1 to 5 with $1=$ no barrieror does not inhibit and $5=\mathrm{a}$ major barrieror strongly inhibits. All items from the SS teaching barriers instrument were examined using principal components factor analysis with varimax rotation. For example, "Not trained in SS', "Financial allocation is adequate for SS". Results revealed two distinct factors, confirming the existence of reliable constructs for teacher-related (Cronbach's alpha $=0.93, \mathrm{n}=8$ ) and institutional related (Cronbach's alpha $=0.78, \mathrm{n}=6$ ) barriers.

Teacher Attitudes Toward SS. An 8-items scale was used to determine SS teachers' feelings toward SS, which used 5-point Like rt-type scale from $1=$ strongly disagree to $5=$ strongly agree. For example, "I like to teach SS". All items were subjected to factor and reliability analysis, results indicated a reliable construct for Attitude to Teaching SS (Cronbach's alpha $=0.89, \mathrm{n}=8$ ). All items for teachers' attitude toward SS instrument were examined using principal components factor analysis with varimax rotation.

\section{Data Collection ANd Analysis}

The collection of data was through mailing of questionnaires to the listed secondary schools. The quantitative data were analyzed using SPSS (version 21.0). All variables satisfied normality criteria and were examined using relevant tests. Two types of statistical techniques were used to analyze the data, namely, descriptive and inferential statistics.

Descriptive statistics were used to analysed gender, age, years of SS teaching experience, academic qualification, field of specialization, level of preparedness, and attendance at SS Orientation Course. Several inferential statistics such as t-tests and analysis of variance (ANOVA) were used to analyze the relationships among selected variables. T-tests were used to contrast mean scores for key variables in terms of gender and attendance in SS orientation course. One-way ANOVAs were used to examine differences between SS teachers' age categories, field of specialization, level of preparedness on TR barriers, IR barriers and attitude toward teaching SS. All t-test and ANOVA in this study were carried out using SPSS for Windows (ver.21). All tests of significance were at the .05 level . For the one-way ANOVA, where F-tests were significant, a post-hoc test using the Tukey-HSD test was employed.

\section{RESULTS AND INTERPRETATIONS}

\section{A. Factor Analysis of the Instrument}

A principle component analysis, a statistical technique applied to a single set of variables, to discover whether specific variables within a set of factors form coherent subsets of factors that are relatively independent of one another was performed on the data [6]. To achieve this, only those components with an eigenvalue greater than 1.0 were retained and rotated [7] with varimax rotation. The 3 factors that emerged were: Factor 1 - teacher related barriers toward sport science; Factor 2 - institutional barriers toward sport science and Factor 3 - attitude toward the teaching of sport science. The 3 factors are described as below.

Teac Teacher related barriers toward sport science (8 items) (Factor 1 ) reflected those items indicating difficulties during the teaching of sport science subjects. Institutional related barriers (6 items) (Factor 2) comprised of items indicating barriers beyond the control of teachers. Attitude toward the teaching of sport science ( 8 items) (Factor 3) was made up of items that contribute to teachers' attitude toward the teaching of sport science. A total of 24 items were identified to represent attitude and barriers toward sport science. Before examining the relationships among variables, we 
performed data reduction for each major categories of items. Subsequently, an exploratory factor analysis, to identify relationships among the items by reducing them into a few relatively independent, but conceptually meaningful, composite variables called components. A varimax rotation was used for the factor analyses. The factor analysis yielded three components which was identified as Teacher related barriers (Component 1), Institutional related barriers (Component 2) and Attitude toward the teaching of Sport Science (Component 3). The loadings of different items are summarized in Table 1.

TABLE 1

PRINCIPAL COMPONENT ANALYSIS OF BARRIERS AND ATTITUDE TOWARD THE TEACHING OF SPORT SCIENCE

\begin{tabular}{lccc}
\hline \multicolumn{1}{c}{ Items } & \multicolumn{1}{c}{ Component } \\
& \multicolumn{1}{c}{3} & \\
\hline Could not understand Sports Science Syllabus & .926 & \\
Unable to plan daily lessons & .876 & \\
Could not understand Sports Science Syllabus specifications & .875 & \\
Not trained in subjects taught (sports Science) & .803 & \\
Unable to prepare test and exam question & .784 & \\
Lacking in knowledge of subjects matter & .760 & \\
Unable to complete the topics in the syllabus & .730 & \\
Unable to control class & .708 & .804 \\
Inadequate teaching aids for the teaching of Sports Science classes & & .748 \\
Inadequate reference books on Sports Science & & .715 \\
Inadequate reference books on Sports Science in National Language & & .631 \\
Inadequate funds allocated for Sports Science & .621 \\
Inadequate facilities for Sports Science classes & .614 \\
Unsuitable Sport Science reference books & & \\
If given a choice, I would prefer to teach other subject & & .873 \\
I like to teach Sport Science & & .858 \\
Teaching Sport Science increase my workload & & .798 \\
I do not like to teach Sport Science & & .786 \\
AI always look for new ideas to teach Sport Science to make it more & .765 \\
interesting & & .701 \\
It is a pressure for me to complete the syllabus & & .609 \\
I feel bored the longer I remain teaching Sport Science & .515 \\
In my opinion, the implementation of Sport Science has been a success & & \\
\hline
\end{tabular}

\section{B. Description of SS Teachers}

The results revealed that there were more male (80.9\%) than Female (19.1\%) SS teachers. By age, the majority of respondents $(56.4 \%)$ were between 30 - 39 years in age. About $85.1 \%$ of the SS teachers were below 40 which reflected that the SS teachers were young. A large number of teachers $(54.3 \%)$ were trained in Sports Science and 36.2 per cent were trained in Physical Education (PE). This indicates that there is no shortage of SS teachers because the PE teachersare capable of teaching SS subject. One third of the total number of SS teachers had less than 1 year teaching experience as SS teachers, majority $(57.4 \%)$ have $1-2$ years teaching experience in teaching SS subject, thus showing that they were new Sport Science teachers. On the contrary only 13.9 per cent of the respondents had 3 years and above experience in teaching SS. Only 69 percent of the Sports Science teachers (65 teachers) has attended the SS Orientation Course before teaching SS subjects. This did not augur well as SS is a new subject introduced to school. In terms of teaching preparedness, almost $65 \%$ was poorly prepared and $35 \%$ was prepared and averagely prepared to teach SS.

\section{Attitude toward the Teaching of SS}

In terms of attitude toward the teaching of SS, 90\% 'strongly agree' and 'agree' that they liked teaching SS. About 76\% 'disagreed' and 'strongly disagreed' SS increased their workload. Almost $62 \%$ 'strongly agree' and 'agree' that the implementation of SS has been a success, and only $34 \%$ felt they were under pressure to complete SS syllabus and almost 78\% 'disagree' and 'strongly disagree' they were bored the longer they remained teaching SS. In fact, almost $91 \%$ always looked for new ideas to teach SS.

Attitude scale was computed using the 8 attitude items related to the teaching of sport science and $\mathrm{t}$ tests and ANOVAs conducted using attitude as dependent variable revealed non-significant results in terms of gender $(\mathrm{t}=1.032, \mathrm{p}=0.314)$, attendance in SS orientation course $(\mathrm{t}=0.056, \mathrm{p}=0.956)$. In addition, ANOVAs results indicated non-significant results in terms of age groups $(\mathrm{F}=0.913$, $\mathrm{p}=0.405)$, field of specialization $(\mathrm{F}=1.125, \mathrm{p}=0.353)$, working experience $(\mathrm{F}=1.252, \mathrm{p}=0.296)$ and significant result in terms of preparedness $(\mathrm{F}=14.887, \mathrm{p}=0.00)$. However post-hoc was not executed for preparedness. 
TABLE2

THE ATTITUDE OF SPORTS SCIENCE TEACHERS' PERCEPTION DNTEACHING SPORTS SCIENCE

\begin{tabular}{|c|c|c|c|c|}
\hline \multirow[b]{2}{*}{ Statements } & \multicolumn{4}{|c|}{ Extent of Agreement in Percentage } \\
\hline & SA A & $\mathrm{U}$ & D & SD \\
\hline If given a choice, I would prefer to teach other subject & 2.18 .5 & 13.8 & 34.0 & 41.5 \\
\hline I like to teach Sport Science & 60.629 .8 & 5.3 & 3.2 & 1.1 \\
\hline Teaching Sport Science increase my workload & $5.3 \quad 5.3$ & 13.8 & 39.4 & 36.2 \\
\hline Ido not like to teach Sport Science & 1.11 .1 & 7.4 & 28.7 & 61.7 \\
\hline AI alvays Look for new ideas to teach Sport Science to make it more interesting & $30.9 \quad 59.6$ & 6.4 & 3.2 & 0.0 \\
\hline It is a pressure for me to complete the syyllabus & $6.4 \quad 27.7$ & 13.8 & 36.2 & 16.0 \\
\hline I feel bored the longer I remain teaching Sport Science & 1.14 .3 & 17.0 & 35.1 & 42.6 \\
\hline In my opinion, the implementation of Sport Science has been a success & $4.3 \quad 57.4$ & 28.7 & 7.4 & 2.1 \\
\hline
\end{tabular}

\section{Barriers to the Delivery of SS Lessons}

The questionnaire required SS teachers to indicate the degree to which certain factors were barriers or inhibited SS program delivery. Table 1 provides a summary of the 14 most substantial factors that influenced the teaching of SS. Seven of eight teacher related (TR) barriers were major strength barriers. All the six institutional (IR) barriers which teachers considered beyond their control and were perceived as moderate to major strength barriers.

TABLE3

BARRIERS TO TEACHING SPORT SCIENCE SUBJECT

\begin{tabular}{lccc}
\hline \multicolumn{1}{c}{ Key barriers ( $\mathrm{n}=94$ ) } & R or TR & M & SD \\
\hline Could not understand Sports Science Syllabus specifications & TR & 4.33 & .771 \\
Unable to control class & TR & 4.32 & .782 \\
Could not understand Sports Science Syllabus & TR & 4.29 & .829 \\
Unable to plan daily lessons & TR & 4.22 & .705 \\
Not trained in subjects taught (sports Science) & TR & 4.14 & .867 \\
Lacking in knowledge of subjects matter & TR & 4.13 & .837 \\
Unable to prepare test and exam question & TR & 4.03 & .994 \\
Inadequate reference books on Sports Science & $\mathbb{R}$ & 4.03 & .971 \\
Inadequate teaching aids for the teaching of Sports Science classes & $\mathbb{R}$ & 4.02 & .816 \\
Inadequate reference books on Sports Science in National Language & $\mathbb{R}$ & 3.97 & .988 \\
Unable to complete the topics in the syllabus & $\mathbb{R}$ & 3.77 & .910 \\
Inadequate funds allocated for Sports Science & $\mathbb{R}$ & 3.67 & 1.076 \\
Inadequate facilities for Sports Science classes & $\mathbb{R}$ & 3.67 & 1.086 \\
Unsuitable Sport Science reference books & $\mathbb{R}$ & 3.12 & 1.104 \\
\hline
\end{tabular}

Note. $\mathbb{R}=$ Institution related; $\mathbb{T R}=$ Teacher related

$1=$ no barrier or does not inhibit, $3=$ moderate barrier, $5=$ a major barrier or strongly inhibits.

TR and IR barriers items were used as dependent variables for inferential statistical analyses. For TR barriers, t-tests revealed non-significant results for all the 8 items in terms of gender but significant result was obtained for 'lacking in knowledge of subject matter' $(t=2.398, p=0.019)$ between those teachers who attended SS orientation course or otherwise. Further scrutiny of the mean scores for the item showed that those attended the orientation course perceived the lack of knowledge as major barrier (mean $=4.27, \mathrm{n}=64$ ) as compared to those who did not attend the course (mean $=3.83$ ). Those who did not attend perceived the lack of knowledge as moderate to major barrier. The ANOVAs conducted showed mixed results. There were no significant results for all the 8 TR barrier items in terms age group, field of specialization. However, ANOVAs revealed significant results for item 'not trained in subject taught' $(\mathrm{F}[3,89]=4.617, \mathrm{p}=0.005)$ in terms of working experience in teaching SS. Similarly in terms of preparedness, significant results were shown for 5 items of 'lack of knowledge in subject matter' $(\mathrm{F}[3,89]=5.022, \mathrm{p}=0.003$, 'not trained in subject taught' $(\mathrm{F}[3,89]=6.227$, $\mathrm{p}=0.001)$, 'could not understand SS syllabus' $(\mathrm{F}[3,89]=4.874, \mathrm{p}=0.003$, 'could not understand SS syllabus specifications' $(\mathrm{F}[3,89]=6.049, \mathrm{p}=0.001$, and 'unable to prepare test and exam questions' $(\mathrm{F}[3,89]=3.874, \mathrm{p}=0.012)$. 
As for IR barriers, t-test in terms of gender revealed significant results for the item 'reference books in SS are suitable' $(t=-2.763, p=0.007)$. Mean scores showed that female (mean=3.76) teachers perceived the suitability of SS reference books as more than moderate barrier and male teachers perceived it (mean $=2.97)$ as low barrier. ANOVAs showed non-significant results in terms of attendance in SS orientation course, age group, field of specialization, preparedness and experience in teaching SS.

\section{DISCUSSION}

To implement effective SS programme, the investigation of teacher's attitude and barriers toward programme implementation are essential.

\section{A. Teacher's Attitude toward the Teaching of SS}

Results in section C indicated that SS teachers were positive toward SS as they liked teaching SS and find ways to improve teaching SS. In addition, majority of them did not feel bored teaching SS, perceived workload as manageable and could complete syllabus without pressure. The positive attitude was supported by inferential statistical results where no difference in attitude among teachers in terms of gender, age groups, field of specialization, working experience except preparedness. The positive attitude of teachers may be explained by the fact they know what outcomes they want to achieve, they then plan how to get these[8]. The result was also supported by [9] who stressed that people's attitudes towards their profession have an effect on their performance. The attitude leads to commitment in wanting to improve SS teaching as emphasized by [10].

In a study of PE teachers, [11] found that PE teachers felt isolated from and undervalued by their schools' administrators, staff, and fellow teachers. Lux also revealed that teachers viewed barriers such as limited time, space, and inadequate facilities and equipment hindered their efforts to perform their job to the best of their ability. Therefore, these findings suggest that school administrators should address and resolve barriers to PE to eliminate the negative impact that these barriers could have on teachers' job performance.

Reference [12] found in the teaching of HIV prevention that attitudes and perceptions of teachers were related to teacher preparation, training and years of teaching in the subject; teacher with least teaching experience had the least supportive attitudes and perceived the most barriers.

\section{B. Teacher Related Barriers toward Sport Science Program Implementation}

Seven of eight teacher related (TR) barriers were major strength barriers except 'unable to complete the topics in the syllabus'. Inferential statistics revealed that teachers attended SS orientation course perceived 'lack of knowledge of subject matter' as major barrier when compared to teachers who did not attend the course. ANOVAs revealed significant results for item 'not trained in subject taught' in terms of working experience in teaching SS. Similarly in terms of preparedness, significant results were shown for 'lack of knowledge in subject matter', 'not trained in subject taught', 'could not understand SS syllabus', 'could not understand SS syllabus specifications', and 'unable to prepare test and exam questions'. This is echoed in the research findings of [13] teaching effectiveness can be accomplished by increasing the level of knowledge and skill that the teacher brings to the instructional process. Similarly, [14] concur that when teachers are asked to teach a new model (eg. sport science) of instruction but they are not adequately equipped with teacher knowledge and skill to support the teaching of the new model, poor implementation of the model would result. The importance of expertise in the implementation of successful academic instruction was supported by [15].

According to [16], one of the school barriers that impedes effective and consistent academic program in schools is the lack of qualified teachers. The importance of training qualified teachers to implement and to teach academic subject was supported by [17] in examining PE in school. Reference [17] stressed that qualified teachers in schools helped maintain consistency in teaching academic subject, make the academic subject relevant in schools and emphasized that professional development that prepares teachers must be the top priority of schools.

The findings of this study was supported by research by [18] on factors affecting teachers' willingness to teach sexual education. Reference [18] found that $37 \%$ of teachers were reluctant to teach because 
of the amount of training received, and 24\% were unwilling to teach because of their knowledge level. Similarly the lack of training and expertise and qualification to provide academic education were acknowledged by previous researchers such as [19, 20,21]

\section{Institutional Related Barriers toward Sport Science Program Implementation}

All the six institutional (IR) barriers which teachers considered beyond their control were perceived as moderate to major strength barriers. Inferential statistical results showed female (mean=3.76) teachers perceived the suitability of SS reference books as more than moderate barrier and male teachers perceived it as low barrier. ANOVAs showed non-significant results in terms of attendance in SS orientation course, age group, field of specialization, preparedness and experience in teaching SS.

The barriers reported in this study was supported by numerous studies on academic program such as PE program $[22,23,11]$ in schools, where it was reported that institutional barriers such as budget cutbacks, lack of access to program funding, lack of access to proper facilities and equipment, poorly maintained facilities, lack of equipment, unqualified teachers, overcrowded classes, and inconsistent implementation of academic program continue to increase. In the study of PE program, [23] found the top three barriers to providing quality PE to be 'access to facilities', 'access to suitable teaching facilities' and 'access to equipment'.

\section{CONCLuSION}

The result of this study should be interpreted in light of limitation in sample size. The sample size was small due to the number of pioneer cohort school in the study was small. Results identified the key factors inhibiting SS teachers, which were categorized as teacher-related (TR) or institutional related (IR). TR barriers revealed that inability to complete the syllabus and inability to prepare exam papers as substantial while IR showed the suitability of SS reference books was the main barrier. Attitude domain was significant in terms of preparedness. This research findings provide invaluable feedbacks to the ministry of education to improve sport science teachers' attitude toward teaching of sport science and to overcome teacher related and institutional related barriers in improving sport science program implementation.

\section{REFERENCES}

[1] J.D. Charlesworth. Educational change in Malaysia: A case study of the implementation of curriculum innovation. Ph.D. Thesis, University of Kentuckey, Lexingon, 1975.

[2] P. Croll \& D. Moses. Perspectives on the National Curriculum in Primary and Secondary Schools. Educational Studies, vol. 16, no.2, pp.187-198, 1990.

[3] D.M. Fetterman, J. Deitz \&N. Gesundheit. Empowerment evaluation: A collaborative approach to evaluating and transforming a medical school curriculum. Academic Medicine, vol. 85, no. 5, pp. 813-820, 2010.

[4] P.D. Lynch \&O. Saifelislam. The Implementation of the New Educational Policy in the Sudan, 1970- 85: promise and reality. Educational Review, vol.41, no.3, 257-261, 1989.

[5] M.C. Schlairet, M.C. Simulation in an undergraduate nursing curriculum: implementation and impact evaluation. The Journal of Nursing Education, vol. 50, no.10, pp.561-568, 2011.

[6] B. Tabachnick \&L. Fidell. Using multivariate statistics, 2nd ed. NY: Harper Collins, 1989.

[7] J.R. Thomasn, J.K. Nelson \&S.J. Silverman. Research methods in physical activity,6th ed. Champaign, IL: Human Kinetics, 2011.

[8] P. Susan. "Issues in Physical Education" Taylor \& Francis Company 11 New Fetter Lane London EC4 P4EE, 29 West 35th Street, New York NY 10001. Available: http://books.google.com.pk, 2000.

[9] D. Asuman\& Oylum, A.C. (2004) "The Attitudes towards Teaching Professions of In-service and Pre-service Primary School Teachers" Pedagogy Studies (Pedagogika), 70, 61-65. Available:www.ceeol.com, 2004.

[10] T.A. Baumgartner, A.S. Jackson, M.T. Mahar \&D.A. Rowe. Measurement for Evaluation in Physical Education and Exercise Science, 5th ed. NY: McGraw-Hill, 2006.

[11] K.M. Lux. How to raise the status of physical education at your school. Journal of Physical Education, Recreation \& Dance, vol.81, no. 8,pp. 40-56. Available: http, 2010. 
[12] S.W. Herr, S.K. Telljohann, J.H. Price, J.A. Dake \&G.E. Stone. High school health-education teachers' perceptions and practices related to teaching HIV prevention. Journal of school health, vol, 82, no.11, pp. 515-521, 2012.

[13] E.A. City, R.F. Elmore, S.E. Fiarman \&L. Teitel. Instructional rounds in education. A network approach to improving learning and teaching. Cambridge, MA: Harvard Education Press, 2010.

[14] D. Sidentop, P. Hastie \&H. van der Mars. Complete guide to sport education. Champaign, IL: Human Kinetics, 2011.

[15] Kanyimba, A., Hamunyela, M. \& Kasanda, G.D. (2014). Barriers to the implementation of education for sustainable development in Namibia's higher education institutions. Creative Education, 5, 242-252.

[16] P.J. Morgan \&V. Hansen. Classroom teachers' perceptions of the impact of barriers to teaching physical education on the quality of physical education programs. Research Quarterly for Exercise and Sport, 79(4), 506-516. Available: http://www.aahperd.org/rc/publications/rqes, 2008.

[17] Shape of the nation report. Status of physical education in the USA. Reston, VA. Available: http://www.aahperd.org/naspe/publications/upload/Shape-of-the-Nation-2010- Final.pdf, 2010.

[18] J.N. Cohen, E.S. Byers \&H.A. Sears. Factors affecting Canadian teachers' willingness to teach sexual health education. Sex Education, vol.12, no. 3,pp. 299-316, 2012.

[19] K. De Corby, J. Halas, S. Dixon, L. Wintrup \&H. Janzen. (2005). Classroom teachers and the challenges of delivering quality physical education. The Journal of Educational Research, vol.98, no.4, pp. 208-220, 2005.

[20] P.J. Morgan \&S.F. Bourke. (2005). An investigation of pre-service and primary school teachers' perspectives of PE teaching confidence and PE teacher education. ACHPER Healthy Lifestyles Journal, vol.52, no.1, pp. 7-13, 2005.

[21] P. Xiang, S. Lowy\&R. McBride (2002). The impact of a field-based elementary physical education methods course on preservice classroom teachers' beliefs. Journal of Teaching in Physical Education, vol.21, no. 2, pp. 145-161, 2002.

[22] Alberta Education. Daily physical activity survey report. 1-105. Available: http://ww.education. alberta.ca/media/756341/dpasurveyreport.pdf, 2008.

[23] K.A. Jenkinson \&A.C. Benson. Barriers to providing education and physical activity in Victorian state secondary schools. Australian Journal of Teacher Education, vol. 35, no. 8, 1-17. Available: http:// www.ajte.education.ecu.au, 2010. 